layers covering the former. The staining reactions and the appearances at a rupture indicate that the thin anterior layer is the truly elastic part of the membrane and that, developmentally, it may be derived from the posterior corneal lamellae, while the two broader posterior layers are the only part derived from the endothelium.

4. The bearing of these observations upon the questions of the regeneration and of the elasticity of the membrane are discussed.

j. When the boy was 12 years of age the eye sustained an accident which was followed by sympathetic ophthalmitis. The numerous pathological signs of this are mentioned.

\title{
REFERENCES
}

RiNGLAND ANDERSON (1939).-Hydrophthalmia or Congenital Glaucoma. E. von Hippel (1928).-In Wessely's Path. Anat. of the Eye, Vol. I, p. 322. Wolff and Lyle (1932).-Proc. Roy. Soc. Med., Vol. VI, p. 701.

TALBOT (1938).-Brit. Jl. Ophthal., Vol. XXII, p. 210.

CoATs (1907).-Trans. Ophthal. Soc. U.K., Vol. XXVII, p. 48.

Loewenstein (1941a).-Lipoids within the ocular tissue. Monograph.

Loewenstein (1941b).-Brit. Jl. Ophthal., Vol. XXV, p. 360.

EisLers (1930). - In Kurzes Handbuch, Vol. I, p. 53.

\section{CENTRAL RETINITIS IN A GIRL AGED EIGHTEEN YEARS. RECOVERY}

BY

ROSA FORD

LONDON

THE prognosis in choroiditis is usually bad as regards the area affected. As Duke-Elder ${ }^{1}$ states, " . . . despite any type of treatment, the lesion involves a complete and irremediable destruction of the area involved ..." When this area is central, the resultant loss of central vision makes the outlook hopeless.

The aetiology is frequently uncertain, and while we are occupied with the often prolonged search for one of the multiple possibilities of septic foci which may be responsible, the damage is done.

The report of a case in which recovery occurred may therefore be useful.

M.A., aged 18 years, when first seen at the South London Hospital for Women in January 1934, had a small patch of

1. Duke-Elder, Vol. III, p. 2249. 
choroiditis in the right fovea which, in 3 days, had reduced vision to $<6 / 60$. The left fundus was normal and vision in this eye was $6 / 6$, but the next day, i.e., 4 days after the onset in the R.E., a similar rather larger patch began to develop in this eye also. On this day she was admitted.

The cause was obscure. The patient considered herself perfectly healthy and had not had any recent illness. My colleagues at hospital who kindly examined her, could find nothing to account for the condition. Every investigation, medical, dental, nasal, $\mathrm{X}$-Ray of the sinuses and the Wassermann was reported negative.

Experience with another similar case, however, had made me suspect that though clinically and radiologically the sinuses appeared normal, they might, nevertheless, contain hidden septic infection.

This other case, a man aged 49 years, was first seen in 1920 because for 2 days his left vision had been impaired. In this eye was a small patch of choroiditis close to the fovea, similar to that seen in M.A. except that on the fringe of the pigmented and pale spots were some minute haemorrhages. Vision was $6 / 60$. Three and a half years later, his right vision having become dim for two days, a similar patch was seen in that fundus, rather to the side of the fovea, so that central vision was still $6 / 6$. During the next year, as the choroiditis spread towards the fovea, it gradually sank to $6 / 24$, the left vision then being $<6 / 60$.

He remained under observation for 16 years during which time extensive areas of choroidal atrophy developed in both fundi and only a little peripheral vision remained.

The cause was again completely obscure. He was a perfectly healthy man and remained so, and, though every kind of specialist had been consulted and every investigation made, nothing to account for the eye condition was ever discovered.

But at one time there had been a check to the progress of the disease lasting for over 2 years. After a submucous resection of the septum, undertaken purely empirically, right vision rose from $6 / 24$ to $6 / 9$ and, after a negative irrigation of the antra eight months after the resection, it rose to $6 / 6$ and so remained for the next year and eight months. For over a year no fresh lesions were observed in either fundus. The case is reported more fully in the Proceedings of the Royal Society of Medicine, March 1929, p. 622.

It was this, the sole success of any treatment, which had led me to think that in M.A. the cause might lie in infected sinuses in spite of the negative clinical and radiological findings, and I determined to try to promote drainage of the sinuses.

Beginning on the fourth day from the first onset, a small piece of wool soaked in peroxide was placed in each side of the nose every morning and left there for 20 minutes. She was also given 
three inhalations of Friar's balsam and took 6 grs. of pulv. aloes barb. daily.

The improvement which followed was as rapid as had previously been the progress of the disease. In four days the central scotoma in the R.E. which had extended $15^{\circ}$ from the fixation point, had dwindled to $5^{\circ}$. In the left eye there was still a paracentral scotoma extending $22^{\circ}$ from the F.P. Left vision was 6/18 and was probably already recovering.

After three more days, the right scotoma had disappeared and the left had become minute; a week later this too had vanished.

Twenty-four days from the first onset, vision was 6/6 (every letter) in both eyes and only the pigmented area in each fundus remained as a permanent scar.

The peroxide and aloes treatment was continued for two years, the patient fearing to discontinue it. Her health remained excellent and she scored over her fellow students at college by escaping the colds from which they frequently suffered.

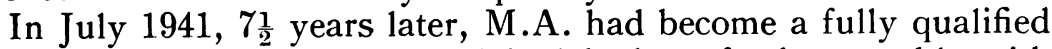
Domestic Science Teacher and had had no further trouble with her eyes.

\section{Conclusions}

1. The prompt recovery following nasal treatment seems to confirm the view that a septic focus in the sinuses was responsible for the choroiditis. It follows that a negative clinical and radiological report is not conclusive evidence against the existence of infection in the sinuses.

2. The initial rapid advance of the choroiditis leads one to think that without the nasal treatment, irreparable damage might have been done to the overlying retina and that the subsequent course might possibly have been similar to that of the man. That we were able to begin treatment as early as the fourth day of the disease made the complete cure possible.

3. The completeness and permanence of the result indicate that the treatment was effective in subduing the sinus infection and was probably safer than operative treatment would have been at the time, as any traumatic exacerbation of the inflammation in the sinuses might have led to an increase of the eye lesion. It is important, however, to note that peroxide packs are not suitable for all patients. In some cases, other measures to promote nasal drainage are more successful. 